\title{
Effect of Lead Nanoparticles Inhalation on Bone Calcium Sensing Receptor, Hydroxyapatite Crystal and Receptor Activator of Nuclear Factor-Kappa B in Rats
}

\author{
Rendra Leonas ${ }^{1}$, Zairin Noor ${ }^{2}$, \\ Hermawan Nagar Rasyid ${ }^{3}$, \\ Tita Husnitawati Madjid ${ }^{4}$, and \\ Fachry Ambia Tanjung ${ }^{3}$
}

'Department of Orthopaedics and Traumatology, Moh. Hoesin Hospital, Medical Faculty Sriwijaya University, Palembang, South Sumatera, Indonesia.

${ }^{2}$ Research Center for Osteoporosis, Department of Orthopaedics and Traumatology, Ulin General Hospital, Medical Faculty Lambung Mangkurat University, Banjarmasin, South Kalimantan, Indonesia.

${ }^{3}$ Department of Orthopaedics and Traumatology, Hasan Sadikin General Hospital, Medical Faculty Padjadjaran University, Bandung, West Java, Indonesia.

${ }^{4}$ Department of Obstetrics and Gynecology, Hasan Sadikin General Hospital, Medical Faculty Padjadjaran University, Bandung, West Java, Indonesia.

Corresponding author: Rendra Leonas, MD. Department of Orthopaedics and Traumatology, Moh. Hoesin Hospital, Medical Faculty Sriwijaya University, Palembang, South Sumatera, Indonesia. Address: JI. Jenderal Sudirman Km 3.5, Palembang, South Sumatera, Indonesia. E-mail: rendraleonas@ yahoo.com

doi: 10.5455/aim.2016.24.343-346 ACTA INFORM MED. 2016 OCT; 24(5): 343-346 Received: AUG 25, 2016 • Accepted: OCT 11, 2016

(C) 2016 Rendra Leonas, Zairin Noor, Hermawan Nagar Rasyid, Tita Husnitawati Madjid, and Fachry Ambia Tanjung

This is an Open Access article distributed under the terms of the Creative Commons Attribution Non-Commercial License (http:// creativecommons.org/licenses/by-nc/4.0/) which permits unrestricted non-commercial use, distribution, and reproduction in any medium, provided the original work is properly cited.

\begin{abstract}
This study aimed to investigate whether $\mathrm{Pb}$ nanoparticle exposure affects the bone calcium sensing receptor (CaSR), hydroxyapatite crystal, and receptor activator of nuclear factor-kappa B (RANK) in rats exposed to subchronic and chronic inhalation. Thirty two rats were randomly divided into eight groups. One group is a non-exposed group. While three groups were exposed to nanoparticles $\mathrm{Pb}$ at the following doses $6.25 ; 12.5$; or $25 \mathrm{mg} / \mathrm{m}^{3}$ an hour daily for 28 days. Another three groups were exposed to nanoparticles $\mathrm{Pb}$ at following doses $6.25 ; 12.5$; and $25 \mathrm{mg} / \mathrm{m}^{3}$ one hour daily for 6 months. The expression of trabecular CaSR was significantly decreased at the all doses subchronic exposure compared to the control group $(P<0.05)$. The CaSR expression significantly decreased in second and third doses subchronic exposure groups compared to the control groups $(P<0.05)$. With subchronic exposure, the crystal size was increased in second dose group and decreased in lowest and highest doses compared to the control (untreated) group. The crystal size and c-axis were decreased in all dose chronic exposures compared to the control (untreated) group. The expression of cortical RANK was significantly lower at the two lowest dose chronic exposures compared to the control group $(P<0.05)$. In conclusion, $\mathrm{Pb}$ nanoparticle inhibit hydroxyapatite crystal growth at least a part via down regulation of CaSR and RANK. Key words: inhalation; crystal; calcium sensing receptor; trabecular; cortical.
\end{abstract}

\section{INTRODUCTION}

Lead $(\mathrm{Pb})$ is a heavy metal that is more widespread than any other metal. $\mathrm{Pb}$ can enter the human body through the respiratory and digestive tract (1). $\mathrm{Pb}$ has been postulated to be stored in the three parts of the body, including blood, soft tissue, and bone. $\mathrm{Pb}$ which located in the bone with a half-life of $30-40$ years. $\mathrm{Pb}$ follow the path of calcium to enter the cells of the body (2). Modeling using the crystal marker indicates that the incorporation of $\mathrm{Pb}$ into trabecular bone hydroxyapatite crystals will increase density and decrease in bone porosity. This indicates that exposure to $\mathrm{Pb}$ will improve the quality of trabecular bone. $\mathrm{Pb}$ competes with divalent ions when the absorption of nutrients. Some examples of the divalent ions are calcium and zinc. $\mathrm{Pb}$ competes with calcium, disrupt the regulation of cell metabolism by binding to receptors, second-messenger calcium, calcium transport blocking the calcium channels and calcium-sodium pump, as well as competing in the calci- um-binding protein (3).

The calcium-sensing receptor (CaR) is a member of the superfamily of $G$ protein-coupled receptors (4). The calcium-sensing receptor $(\mathrm{CaR})$ is a seven transmembrane domain G-protein coupled receptor that was initially characterized as the sensor responsible for modulating parathormone and calcitonin release in response to changes in blood calcium levels (5). However, the $\mathrm{CaR}$ is more than just a calcium sensor; it is a fairly broad spectrum sensor of small cationic molecules, capable of transducing signals in response to changes in the concentration of heavy metals, including lead and cadmium (6), as well as cationic amino acids (7). Receptor activator of NF-kB, alternately identified as TNF-related activation-induced cytokine receptor (TRANCE-R) or osteoclast differentiation and activation receptor (ODAR) is the signaling receptor for RANKL. RANK has been designated TNFRSF11A, and is a type I 616 amino acid homo-trimerizing transmembrane 
protein containing four extra-cellular cysteine-rich pseudorepeats. Trimerization is promoted by interaction with RANKL. RANK is strongly induced, especially in OC precursor cells, by M-CSF [8-11]. As far as we know, there is no study evaluating the effect $\mathrm{Pb}$ nanoparticle on bone $\mathrm{CaSR}$ and RANK expression, Therefore, this study aims to investigate whether $\mathrm{Pb}$ nanoparticle exposures affects the bone CaSR, hydroxyapatite crystal, and RANK in rats exposed to subchronic and chronic inhalation.

\section{MATERIAL AND METHODS}

\section{Animals}

Male Wistar albino rats, 16 weeks of age, weighing 175200 grams, were used for this study. Thirty two rats were randomly divided into eight groups. One of the group is the non-exposed group. Three groups were exposed to $\mathrm{Pb}$ nanoparticles at doses of $6.25 ; 12.5$; or $25 \mathrm{mg} / \mathrm{m}^{3}$ an hour daily for 28 days. Another three groups were exposed to $\mathrm{Pb}$ nanoparticles at doses of $6.25 ; 12.5$; and $25 \mathrm{mg} / \mathrm{m}^{3}$ one hour daily for 6 months. Animals were kept in a clean wire cage and maintained under standard laboratory conditions with a temperature of $25 \pm 3^{\circ} \mathrm{C}$ and dark/light cycle $12 / 12 \mathrm{~h}$. Standard diet and water were provided ad libitum. Animals were acclimatized to laboratory conditions for two weeks prior to the experiment. Animal care and experimental procedures were approved by the institutional ethics committee of Faculty of Medicine, Padjadjaran University, Bandung, West Java, Indonesia.

\section{$\mathrm{Pb}$ Nanoparticles exposure}

$\mathrm{Pb}$ nanopowder was purchased from Intelligent Materials Pvt. Ltd (Nanoshell LLC, Wilmington, DE, US). The concentration of nanoparticles $\mathrm{Pb}$ exposure was determined according to occupational exposure in upper ground coal mining areas in South Kalimantan, Indonesia (12-15) and Turkey (16). The exposure chamber was designed and is available in the Laboratory of Pharmacology, Faculty of Medicine, Brawijaya University. The principal work of the chamber is to provide an ambient resuspended $\mathrm{PM}_{10}$ coal dust, which can be inhaled by rats. Chamber size was $0.5 \mathrm{~m}^{3}$ and flowed by a $1.5-2 \mathrm{~L} / \mathrm{min}$ airstream that resemble the environmental airstream. To prevent hypoxia and discomfort, we also provide oxygen supply was also provided in the chamber. The non-exposed group was exposed to filtered air in the laboratory.

\section{Tissue sampling}

At the end of the treatment, the animals were euthanized by anesthetizing with ether inhalation. The femur was collected, weighed, and washed with physiological saline. All femur samples were labeled and stored at $-80^{\circ} \mathrm{C}$ until analysis.

\section{Labeling immunofluorescence staining of CaSR}

Paraffin-embedded femur sections (10 $\mu \mathrm{m}$ thick) were immunostained according to the manufacturer's instructions (Santa Cruz Biotechnology, Dallas, TX, USA). Briefly, lung sections were deparaffinized in xylene and dehydrated through a graded ethanol series. Nonspecific protein bindings were blocked with $2 \%$ skim milk powder in PBS at RT for $20 \mathrm{~min}$, followed by washing with PBS. Next, femur sections were incubated with rabbit anti-CaSR polyclonal (Santa Cruz Biotechnology) antibodies at specified dilu- tions for $1 \mathrm{~h}$, followed by washing with PBS. The primary antibody bindings were then detected with goat anti-rabbit Rhodamine (Santa Cruz Biotechnology) and goat anti-mouse FITC (Santa Cruz Biotechnology) antibodies at specified dilutions for $1 \mathrm{~h}$ in the dark, followed by washing with PBS. All PBS washed steps consisted of three washes of 5 min each. The expressions of CaSR were analyzed by counting fluorescent intensity of cells (in arbitrary units; AU) in five random high-power $(\mathrm{x} 400)$ microscope fields. The fluorescent images were recorded under a confocal laser scanning microscope (Olympus).

\section{Analysis of bone hydroxyapatite crystal}

Characterization of the X-ray diffraction results was performed by means of PANanalytical X'Pert PRO-MPD. Subsequent analysis was by means of the software programs High Score Plus, Crystal Maker and DDVIEW, complemented with the latest version of PDF2. Diffraction spectra were recorded at an angle of $2 \theta$, from 200 to 60 o, with a $\mathrm{Cu}-\mathrm{K}$ a radiation source (wave length $=1.54056 \AA, 40 \mathrm{~mA}, 40 \mathrm{kV}$ ) and step size of $0.05^{\circ}(17)$.

\section{Statistical analysis}

Data are presented as mean \pm SD and the differences between groups were analyzed using one-way analysis of variance (ANOVA) with SPSS 15.0 statistical package for Windows. Only probability values of $p<0.05$ were considered statistically significant different and later subjected to Tukey's post hoc test.

\section{RESULTS}

Figure 1 presents the trabecular CaSR expression in subchronic and chronic exposure groups. The expression of trabecular CaSR was significantly decreased at the all doses subchronic exposure compared to the control group $(\mathrm{P}<0.05)$. There is no significant differences between these three doses of subchronic exposure $(\mathrm{P}>0.05)$. We found no significant difference in the expression of trabecular CaSR in chronic exposure groups compared to control group $(\mathrm{P}>0.05)$.

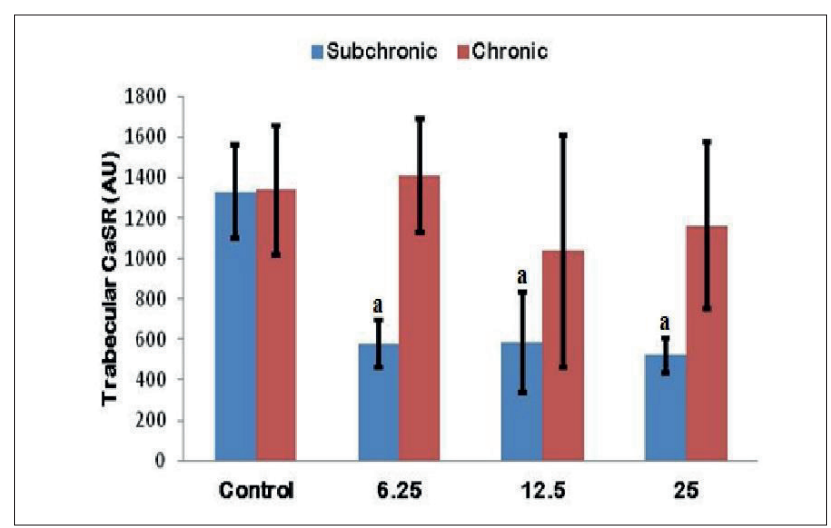

Figure 1. The expression of trabecular CaSR in each experimental group. Note: Values are presented as mean \pm standard deviations; a $p$ $<0.05$ compared to the control group; CasR: calcium sensing receptor; $\mathrm{AU}$ : arbitrary units; dose exposure in $\mathrm{mg} / \mathrm{m} 3$.

Figure 2 presents the expression of cortical CaSR in each experimental group. The CaSR expression significantly decreased in second and third doses subchronic exposure groups compared to the control groups $(\mathrm{P}<0.05)$. The expression of cortical CaSR was not significant differences between chronic exposure group $(\mathrm{P}>0.05)$. 


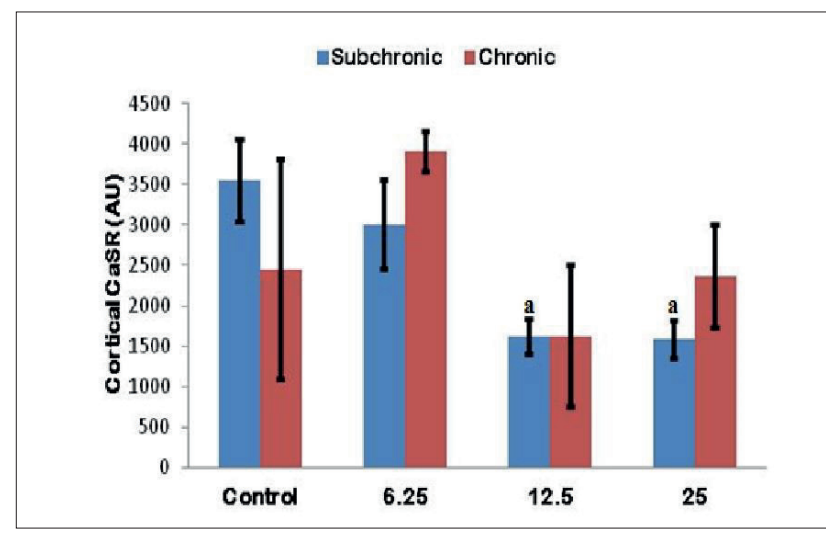

Figure 2. The expression of cortical CaSR in each experimental group. Note: Values are presented as mean \pm standard deviations; a $p<0.05$ compared to the control group; CasR: calcium sensing receptor; $\mathrm{AU}$ : arbitrary units; dose exposure in $\mathrm{mg} / \mathrm{m} 3$.

Figure 3 presents the trabecular RANK expression in subchronic and chronic exposure groups. In subchronic exposure, the trabecular RANK expression was not significant difference between groups $(\mathrm{P}>0.05)$. We also found no significant difference of this expression in chronic exposure groups compared to control group $(\mathrm{P}>0.05)$.

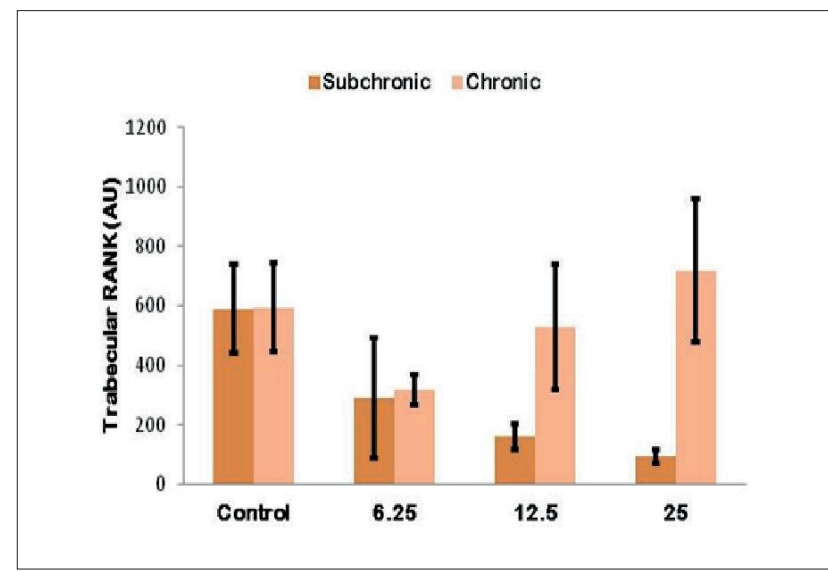

Figure 3. The expression of trabecular RANK in each experimental group. Note: Values are presented as mean \pm standard deviations; RANK: receptor activator of nuclear factor-kappa B; AU: arbitrary units; dose exposure in $\mathrm{mg} / \mathrm{m} 3$.

Figure 4 presents the cortical RANK expression in subchronic and chronic exposure groups. In subchronic exposure, the cortical RANK expression was not significant difference between groups $(\mathrm{P}>0.05)$. The expression of cortical RANK was significantly lower at the two lowest dose chronic exposures compared to the control group $(\mathrm{P}<0.05)$. Figure 5 present the crystal size and lattice parameters in subchronic exposure. The crystal size was increased in second dose group and decreased in lowest and highest doses compared to the control (untreated) group. The lattice parameters were different between groups. Figure 6 present the crystal size and lattice parameters in chronic exposure. The crystal size and c-axis were decreased at all doses compared to the control (untreated) group.

\section{DISCUSSION}

The CaSR is present in osteoblasts and osteoclasts and their precursors, as well as bone marrow-derived stromal cells, growth plate chondrocytes, cells of the monocyte-macro-

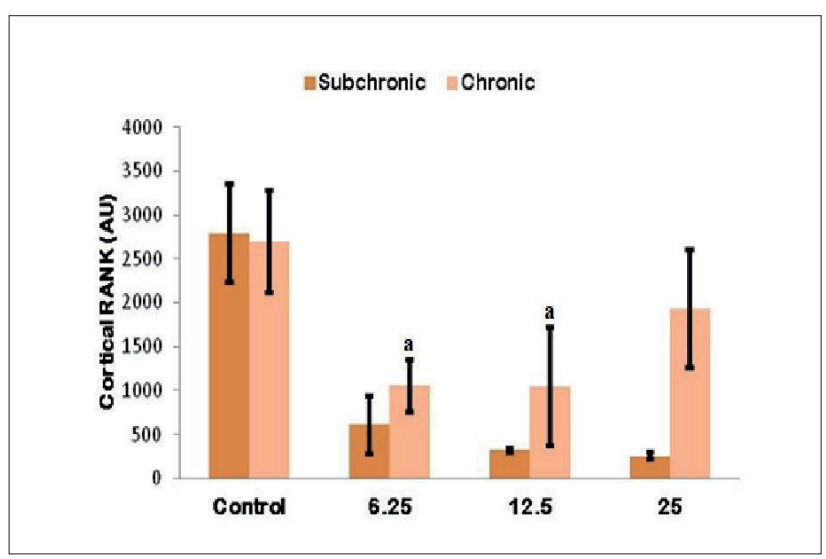

Figure 4. The expression of trabecular RANK in each experimental group. Note: Values are presented as mean \pm standard deviations; a $p<$ 0.05 compared to the control group; RANK: RANK: receptor activator of nuclear factor-kappa B; AU: arbitrary units; dose exposure in mg/m3.

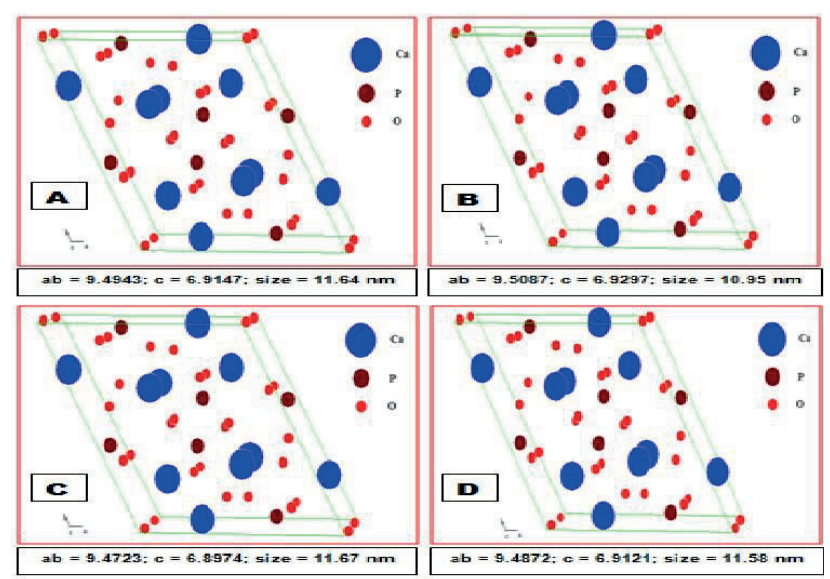

Figure 5. The crystal size and lattice parameters in subchronic exposure. The crystal size was increased $(11.67 \mathrm{~nm})$ in second dose group and decreased in the lowest $(10.95 \mathrm{~nm})$ and highest (11.58 $\mathrm{nm})$ doses compared to the control $(11.64 \mathrm{~nm})$ group. The lattice parameters were different between groups. The c-axis was decreased in two highest doses of subchronic exposure compared with control.

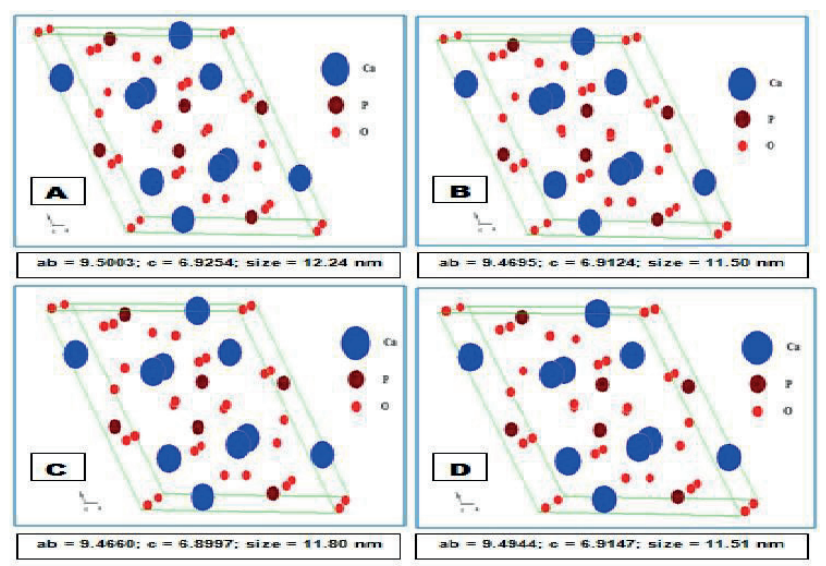

Figure 6. The crystal size and lattice parameters in chronic exposure. The crystal size was decreased in all dose exposure groups compared to the control group. The lattice parameters were different between groups. The c-axis was also decreased in all doses of chronic exposure compared with control.

phage lineage and hematopoietic stem cells (18). The possible involvement of the CaSR in the etiology of osteoporosis, however, large-scale meta analysis of genome wide association data incorporating 150 candidate genes did not link the CaSR to bone mineral density or osteoporosis fracture risk (19). Stimulation through the CaSR leads to increased pro- 
duction of PTHrP a physiological regulator of bone formation having positive effects on osteoblast differentiation and survival $(20,21)$. Our study showed that the expression of trabecular CaSR was significantly decreased at the all doses subchronic exposure compared to the control group $(\mathrm{P}<0.05)$. There was no significant differences between these three doses of chronic exposure $(\mathrm{P}>0.05)$. In cortical femur, the CaSR expression significantly decreased in second and third doses subchronic exposure groups compared to the control groups $(\mathrm{P}<0.05)$. This finding indicated that $\mathrm{Pb}$ nanoparticles may have down-regulated CaSR expression in cortical or trabeculaer bone at critical match dose. This lag phase indicates the complexity of biological system $(22,23)$.

In this study, the crystal size was increased in second dose group and decreased in lowest and highest doses compared to the control group (subchronic exposure). This finding indicated that $\mathrm{Pb}$ nanoparticles modified the crystal size at critical match dose. The grow of mineral in hydroxyapatite crystal occurs under specific orientation in which the c-axis of the crystal is approximately parallel to the length axis of the collagen fiber (24). Specifically, the c-axis were decreased in two highest doses of subchronic exposure compared with control. With chronic exposure, the crystal size and c-axis were decreased in all doses compared to the control (untreated) group. We hypothesized that this crystal growth inhibition was, at least a part involved the down regulation of CaSR.

RANK is a homotrimeric transmembrane protein member of the TNF receptor superfamily (25). In subchronic and chronic exposure, the trabecular RANK expression was not significant difference between groups $(\mathrm{P}>0.05)$. The expression of cortical RANK was significantly lower at the two lowest dose chronic exposures compared to the control group $(\mathrm{P}<0.05)$. Our finding showed that $\mathrm{Pb}$ nanoparticles down-regulated the expression of cortical RANK. This finding indicates that $\mathrm{Pb}$ nanoparticles inhibits signal for osteoclast differentiation and bone resorption.

\section{CONCLUSION}

$\mathrm{Pb}$ nanoparticle inhibit hydroxyapatite crystal growth at least a part via down regulation of CaSR and RANK.

Conflict of interest statement: The author(s) declare(s) that there is no conflict of interest regarding the publication of this paper.

\section{REFERENCES}

1. Kumar V, Abbas A, Fausto N. Robbins and cotran: pathologic basic of disease. 7ed. elsevier. 2005. Philadelphia, USA.

2. Ronis M, Aronson J, Gao G, et al. Skeletal effects of developmental $\mathrm{Pb}$ exposure in rats. Toxicological Sci. 2001; 62: 321-9.

3. Gover RA. Nutrition and metal toxicity. J Clin Nutr. 1995; 61(suppl): 646S-50S.

4. Wang M, Yao Y, Kuang D, Hampson DR. Activation of family C G-protein coupled receptors by the tripeptide glutathione, J Biol Chem. 2006; 281: 8864-70.

5. Brown EM, Gamba G, Riccardi D, Lombardi M, Butters R, Kifor O, Sun A, Hediger M, Lytton J, Hebert S. Cloning, expression, and characterization of an extracellular $\mathrm{Ca} 2+$ sensing receptor from bovine parathyroid, Nature. 1993; 366: 575-580.

6. Handlogten M, Shirashi N, Awata H, Huang C, Miller R. Extracellular $\mathrm{Ca} 2+-$-sensing receptor is a promiscuous divalent cation sensor that responds to lead. Am J Physiol Renal Physiol. 2000; 279 F1083-F1091.
7. Quinn S, Ye CP, Diaz R, Kifor O, Bai M, Vassilev P, Brown E. The Ca2+-sensing receptor: a target for polyamines, Am J Physiol Cell Physiol. 1997; 273: C1315-C1323.

8. Wong BR, Josien R, Lee SY, Vologodskaia M, Steinman RM, Choi Y. The TRAF family of signal transducers mediates NF-kappaB activation by the TRANCE receptor. J Biol Chem.1998; 273(43): 28355-9.

9. Hofbauer LC, Khosla S, Dunstan CR, Lacey DL, Boyle WJ, Riggs BL. The roles of osteoprotegerin and osteoprotegerin ligand in the paracrine regulation of bone resorption. J Bone Miner Res. 2000; 15(1): 2-12.

10. Kanazawa K, Kudo A. Self-assembled RANK induces osteoclastogenesis ligand- independently. J Bone Miner Res. 2005; 20(11): 2053-60.

11. Arai F, Miyamoto T, Ohneda O, Inada T, Sudo T, Brasel K, et al. Commitment and differentiation of osteoclast precursor cells by the sequential expression of c-Fms and receptor activator of nuclear factor kappaB (RANK) receptors. J Exp Med. 1999; 190(12): 1741-54.

12. Kania N, Setiawan B, Widjajanto E, et al. Peroxidative index as novel marker of hydrogen peroxide involvement in lipid peroxidation from coal dust exposure. Oxidant Antioxid Med Sci. 2012; 1(3): 209-15.

13. Setiawan B, Darsuni A, Muttaqien F, et al. The effects of combined particulate matter 10 coal dust exposure and high-cholesterol diet on lipid profiles, endothelial damage, and hematopoietic stem cells in rats. J Exp Integr Med. 2013; 3(3): 219-23.

14. Setiawan B, Darsuni A, Muttaqien F, et al. Cholesterol lowering effect of subchronic inhalation particulate matter 10 coal dust on rats. Med Sci I International Journal. 2013; 1-12. doi: 10.5455/medscience.2013.02.8049.

15. Noor Z, Setiawan B. Subchronic inhaled particulate matter coal dust changes bone mesostructure, mineral element and turn over markers in rats. J Exp Integr Med. 2013; 3: 153-8.

16. Gurel A, Armutcu F, Damatoglu S, Unalacak M, Demircan N. Evaluation of erythrocyte $\mathrm{Na}^{+}, \mathrm{K}+-$ ATPase and superoxide dismutase activities and malondialdehyde level alteration in coal miners. Eur J Gen Med. 2004; 1(4): 22-8.

17. Noor Z, Setiawan B. Subchronic inhaled particulate matter coal dust changes bone mesostructure, mineral element and turn over markers in rats. J Exp Integr Med. 2013; 3(2):153-8.

18. Yamaguchi T. The calcium-sensing receptor in bone. J Bone Miner Metab 2008; 26: 301-11.

19. Richards JB, Kavvoura FK, Rivadeneira F, Styrkarsdottir U, Estrada K, Halldorsson BV, et al. Collaborative meta-analysis: associations of 150 candidate genes with osteoporosis and osteoporotic fracture. Ann Intern Med. 2009;151(8): 528-38.

20. Martin TJ. Osteoblast-derived PTHrP is a physiological regulator of bone formation. J Clin Invest 2005; 115(9): 2322-4.

21. Ahlstrom M, Pekkinen M, Riehle U, Lamberg-Allardt C. Extracellular calcium regulates parathyroid hormone-related peptide expression in osteoblasts and osteoblast progenitor cells. Bone. 2008; 42: 482-90.

22. Klostranec JM, Chan WCW. Quantum dots in biological and biomedical research: recent progress and present challenges. J Adv Mater. 2006; 18(15): 1953-64.

23. Martin P. Wound healing-aiming for perfect skin regeneration. Science. 1997; 276(5309):75-81.

24. Zhao X, Wu Z, Zhang Y, et al. Locally administrated perindopril improves healing in an ovariectomized rat tibial osteotomy model. PLoS One. 2012; 7: doi:10.1371/journal. pone.0033228.

25. Boyce BF, Xing L. Functions of RANKL/RANK/OPG in bone modeling and remodeling. Arch Biochem Biophys. 2008; 473(2):139-146. 